\title{
The relationship between community nutritionists' use of policy, systems and environmental strategies to prevent obesity and its determinants depends on networking
}

\author{
Angela H Lu ${ }^{1}$, Katherine L Dickin ${ }^{1}$, Mark A Constas ${ }^{2}$ and Jamie S Dollahite ${ }^{1, *}$ \\ 'Division of Nutritional Sciences, Cornell University, Ithaca, NY 14853, USA: ${ }^{2}$ Dyson School of Applied Economics \\ and Management, Cornell University, Ithaca, NY, USA
}

Submitted 2 September 2016: Final revision received 13 April 2017: Accepted 21 April 2017: First published online 21 June 2017

\begin{abstract}
Objective: To apply the Theory of Planned Behaviour to examine the relationship between the constructs of background factors and beliefs towards using policy, systems and environmental (PSE) strategies and reported use of PSE strategies to prevent obesity by a group of professional nutrition educators.

Design: Cross-sectional study using self-reported survey.

Setting: Cooperative Extension in New York, USA.

Subjects: Nutrition educators ( $n$ 58); survey response rate $100 \%$.

Results: Nutrition educators' reported use of PSE strategies to prevent obesity were positively associated with background factors of their community networking and number of staff they managed, their belief of other people's expectations of them to make PSE changes and the belief that their communities were ready to use PSE strategies; and negatively associated with their belief that individual-level factors contributed to obesity. The relationships among these variables were complicated and their use of PSE strategies occurred only when they utilized their professional networks at a moderately high level (above mean of 5.3 on a scale of $1-7$ ), given that their community was also ready to use PSE strategies.

Conclusions: Nutrition educators' use of PSE strategies depends on several internal and external factors. Community networking needs to be emphasized as one of the most significant factors contributing to nutrition educators' work in this area. Organizational and community support should be in place in order to facilitate nutrition educators' effective use of PSE strategies.
\end{abstract}

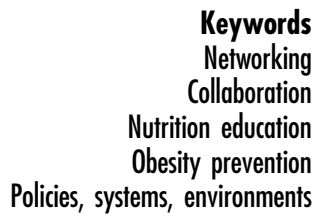

Collaboration

Nutrition education

Policies, systems, environments
Community-based strategies that aim to effect change in policies, systems and environments (PSE) to facilitate healthy eating and physical activity for obesity prevention have become widespread since the early $2000 \mathrm{~s}^{(1,2)}$ and have shown potential to prevent weight gain in the targeted population $^{(3,4)}$. Federal $^{(5,6)}$ and state governments ${ }^{(7)}$ in the USA emphasize the importance of stakeholder collaborations in implementing community-based PSE strategies. Released in 2014, both the National Institute of Food and Agriculture (NIFA) Strategic Plan ${ }^{(8)}$ and Supplemental Nutrition Assistance Program Education (SNAP-Ed) State Plan Guidance ${ }^{(9)}$ urged states to expand nutrition education and obesity prevention interventions to include PSE strategies. NIFA's support for the Expanded Food and Nutrition Education Program (EFNEP), where nutrition educators use a holistic approach to deliver evidenced-based nutrition knowledge and skills to the low-income population in local communities, and the SNAP-Ed programme both aim to establish PSE changes that facilitate the adoption of healthier food and physical activity behaviours. This is especially important for low-income populations that are disproportionately more affected by obesity ${ }^{(10)}$.

As a result of federal programmatic changes, the work of the NIFA-supported Cooperative Extension System that aims to bring research-based knowledge of land-grant universities through local Cooperative Extension organizations to community residents has also changed ${ }^{(8)}$. More and more public health and community organizations, including the Cooperative Extension that deliver the EFNEP and SNAP-Ed programme, have begun or continued to mobilize their resources to promote PSE changes in various settings $^{(11,12)}$ on multiple levels of the socio-ecological continuum $^{(13)}$. Complex multilevel, multi-sector work such as using PSE strategies requires extensive communication, networking and collaboration, requisites of which community members claimed to need more ${ }^{(14)}$. 
On a personal level, Yngve ${ }^{(15)}$ emphasized that networking and collaborating were essential skills for a good public health nutrition leader. Other researchers have echoed the call to increase these skills among public health $^{(16)}$ and Cooperative Extension professionals, who often network with other community organizations to provide direct service and education to local residents. This would facilitate expansion of nutrition educators' traditional roles focused on providing direct education into their roles as agents of PSE change, collaborating with partners, such as local businesses and government officials, who are in positions to effect PSE. Research also indicated that the success of community-based programmes depends on factors such as organizational capacities, community readiness $^{(17)}$ and agency collaborations ${ }^{(18)}$. However, it remains unclear which of the multitude of factors associated with community and public health professionals' use of PSE strategies are the most significant.

Factors associated with the use of PSE strategies by community nutrition educators in Cooperative Extension who oversee the delivery of the EFNEP and SNAP-Ed programmes can be examined by adopting the Theory of Planned Behaviour (TPB) ${ }^{(19)}$ as a guide. According to the TPB, human behaviour results from a person's intention to act, which stems from a set of background factors, salient beliefs, and corresponding attitudes, subjective norms and perceived behavioural control. Background factors include global dispositions, demographic factors and other psychosocial variables that influence behaviour indirectly through people's behavioural, normative and control beliefs ${ }^{(19)}$. Behavioural beliefs are the likely consequences of performing the behaviour; normative beliefs are the perceived expectations of important referent individuals surrounding the person; and control beliefs are the perceptions of the factors that may facilitate or hinder the performance of the behaviour ${ }^{(19)}$. Evaluation of these three sets of beliefs results in their respective constructs: attitude towards behaviour, an evaluation of the behavioural outcome that is either favourable or unfavourable; subjective norm (referred to as 'perceived social norms' in the present study), the perceived social pressure to comply with the expectations of others; and perceived behavioural control, the perceived ease or difficulty in performing the behaviour ${ }^{(19)}$. It is expected that 'the more favorable the attitude and subjective norm with respect to a behavior, and the greater the perceived behavioral control, the stronger should be an individual's intention to perform the behavior under consideration, ${ }^{\text {(19) }}$ (p. 5).

The present study adopted the TPB to examine the factors related to nutrition educators' involvement in Cooperative Extension in using PSE approaches to prevent obesity in organizations and communities. The conceptual framework that guided this research (Fig. 1) illustrates that the relationships between the background factors (independent variables) and nutrition educators' reported use of PSE strategies (dependent variable) are mediated through a set of beliefs variables (mediating variables) towards using PSE strategies. These included beliefs about using PSE strategies (behavioural beliefs), about others' expectations (normative beliefs) and perceived control (control beliefs) over using the strategies based on available resources, such as personal skills and community networking. The study focused on current reported behaviours instead of future intentions because intention does not always translate into behaviour. Identifying the essential elements that contribute to nutrition educators' actions has significant implications for practice in finding ways to affect nutrition educators' perceptions related to their use of PSE strategies for obesity prevention.

\section{Methods}

\section{Sample}

The current cross-sectional, descriptive study was conducted with Cooperative Extension nutrition educators

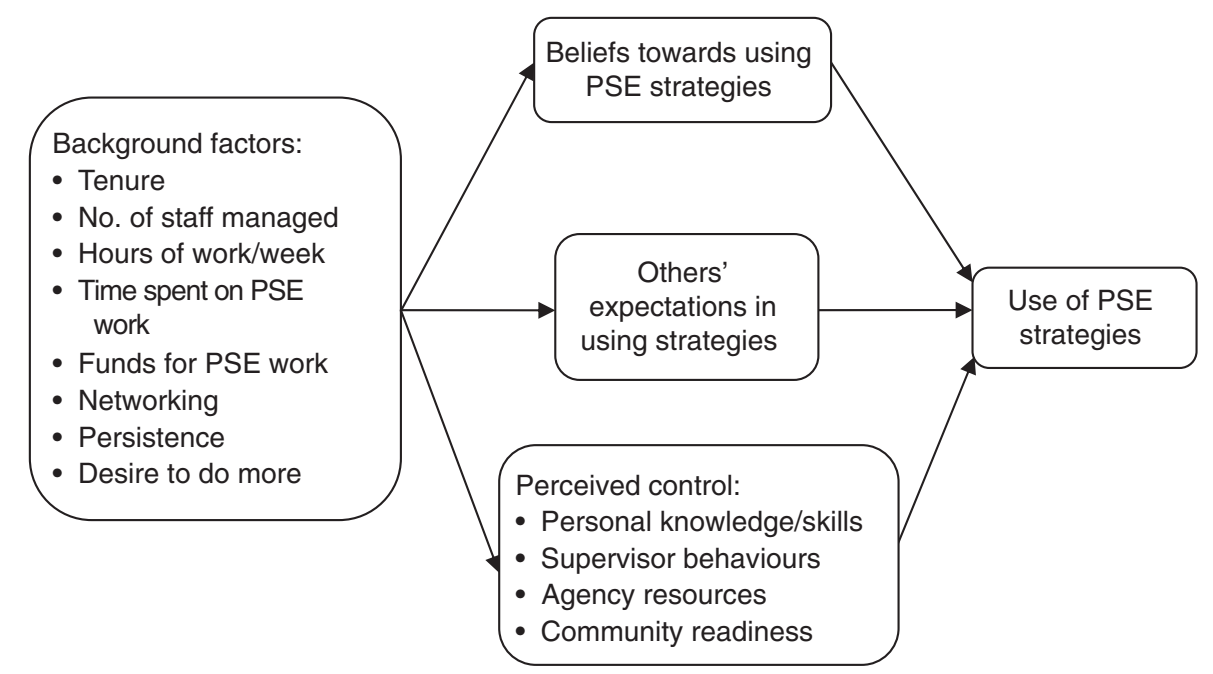

Fig. 1 Conceptual model of nutrition educators' use of policy, systems and environmental (PSE) strategies 
in New York, USA. A sequential mixed-methods approach was used. First, qualitative interviews were conducted with seven nutrition educators, purposefully selected to maximize variation in perspectives and implementation of PSE strategies ${ }^{(20)}$. Four (two rural, two urban) had more experience implementing PSE strategies and three (two rural, one urban) were focused primarily on direct education. Second, a quantitative survey was conducted with all fifty-eight nutrition educators employed in Cooperative Extension in New York across the state at the time of the survey. The minimum education requirement for these nutrition educators was a master's degree. Informed consent was obtained from each nutrition educator. The study was approved by the Cornell University Institutional Review Board.

\section{Survey development}

A 276-item survey was constructed using data from existing literature and findings from the in-depth interviews of the present study. Nutrition educators' involvement in applying PSE strategies and associated facilitators and barriers were extracted from in-depth interviews. These facilitators and barriers were then formulated into a set of survey items according to the TPB constructs as variables related to nutrition educators' use of PSE strategies; for example, belief that using PSE strategies positively impacts obesity, others' views towards using PSE strategies, supervisor's support, perceived community readiness to use PSE strategies, etc. When possible, survey items were derived from published scales from nutrition and organizational behaviour literature. When such scales were not available, items were developed, using the words of nutrition educators from the in-depth interviews to the extent possible. Content validity was established based on review by the authors' research team which had experiential and technical expertise relevant to the nutrition educators' roles and PSE work. Three people, recently but not currently employed as nutrition educators, pilot-tested the survey, recording response time and commenting on item clarity, conciseness ${ }^{(21)}$ and ease of completion. The final variables and associated survey items are described below.

\section{Use of policy, systems and environmental strategies}

Reported use of PSE strategies (dependent variable) was a summative score of the frequency of performing three tasks in each of the four settings (nutrition educators' own workplace, organizations serving adults, schools/youthserving agencies and community committees/coalitions) that were identified in the interviews as most relevant to nutrition educators' PSE work. The specific strategies were summaries of paraphrases captured from a variety of nutrition educators' quotes from the qualitative interview. The tasks increased in intensity of engagement and collaboration with partners towards PSE goals. In the first three settings, the first task was 'to make recommendations and provide information' to colleagues or other agency staff on ways to increase their access to healthy foods and physical activity; the second task was to develop and implement action plans' to make PSE changes to increase agency staff and audience access to healthy foods and physical activity; and the third task was 'to evaluate their progress' in making PSE changes to increase agency staff and audience access to healthy foods and physical activity. In the community setting, the first task was 'to make recommendations and provide information' to the committee/coalition on ways to increase residents' access to healthy foods and physical activity; the second task was 'to support other agencies' projects' that make PSE changes in the community to increase residents' access to healthy foods and physical activity; and the third task was 'to take the lead' to work on PSE projects that increase residents' access to healthy foods and physical activity. Each task was assigned a weighted score ( 1 to 4 ) that was then multiplied by nutrition educators' reported frequency of performing each task $(1=\text { 'almost never' to } 5=\text { 'almost always' })^{(20)}$.

\section{Background factors, beliefs and factor analysis}

Multiple scales were constructed to assess the independent variables of background factors and beliefs in the TPB. Confirmatory factor analysis using principal component methods with varimax rotation was performed to examine and simplify the underlying structures of the independent variables. Items with a loading $>0.6$ on one factor $^{(22)}$ were retained (Table 1 ). To ensure internal reliability, Table 2 shows that each variable contained at least three items with a significant Bartlett's test of sphericity and a Cronbach's $\alpha$ and Kaiser-Meyer-Olkin measure of sampling adequacy of $>0.70$ (except obesity beliefs because such general beliefs are considered an important background factor ${ }^{(19)}$ ).

Background factors. Nutrition educators described tenure, number of staff they managed, hours of work each week, and hours dedicated to and having funds for PSE work as background factors that related to their use of PSE strategies. Additionally, four scales were developed to assess networking, desire to do more, persistence and obesity beliefs. In interviews, 'networking' (five items) and collaborating with partners was reported to be one of the most fundamental and frequent tasks in which nutrition educators engaged in their job. This scale assessed the extent of their networking with community partners for programme delivery. 'Persistence' (five items) reflected nutrition educators' perseverance in various aspects of their work, such as repeatedly urging partners to engage in environmental projects. 'Desire to do more' (four items) denoted nutrition educators' outlook towards future possibilities for programme expansion in their jobs, such as initiating a local coalition to make PSE changes. 'Obesity beliefs' (three items) assessed the extent to which nutrition educators perceived individual-level factors, as opposed to environmental factors, to be contributors to the obesity epidemic. 
Table 1 Items and factor loadings for the background factors and beliefs variables relating to nutrition educators' use of policy, systems and environmental (PSE) strategies

1. In my job, I know and am well connected to a lot of influential leaders ${ }^{(46)}$

2. I am good at using my connections and network to make things happen in my job ${ }^{(46)}$

loading

3. I am knowledgeable of the politics of our partnering agencies

4. I have developed a large network of colleagues and agency partners whom I can call on for support when I really need to get things done ${ }^{(46)}$

5 . I have a lot of freedom to decide what agencies I will collaborate with Persistence

1. If I believe in an idea, no obstacles will prevent me from making it happen ${ }^{(47)}$

2. I excel at identifying opportunities ${ }^{(47)}$

3. I love being a champion for my ideas, even against others' opposition ${ }^{(47)}$

4. I will not stop contacting an agency partner until I hear from them

5. No matter what the odds, if I believe in something I will make it happen ${ }^{(47)}$

Desire to do more

1. I am constantly on the lookout for ways to expand my programme area ${ }^{(47)}$

2. I am always looking for better ways to do things ${ }^{(47)}$

3. I collaborate with agency partners to expand my programmes beyond low-income audiences

4. I collaborate with the specific intent of making sustainable changes in how our community operates

Obesity beliefs

1. Low self-esteem ${ }^{(10,48)}$

2. Hormones/slow metabolism ${ }^{(10,48)}$

3. Lack of willpower ${ }^{(49)}$

Beliefs variables

Beliefs towards using PSE strategies (i.e. impact on obesity prevention)

1. Will increase people's awareness of obesity and its prevention

0.915

0.855

0.796

0.760

2. Will contribute positively to obesity prevention

3. Has great potential in obesity prevention

0.627

Perceived social norms in using PSE strategies (i.e. others' expectations)

1. Falls within the scope of my job

2 . Is a priority in my work agenda

0.843

0.838

0.789

0.756

0.714

3. Is something I am asked to do

0.829

0.796

0.758

0.725

4. Colleagues

5. My staff

6. My supervisor

7. Agency partners

Perceived control (i.e. resources available to support nutrition educators' use of PSE strategies)

Personal knowledge and skills

1. I have the knowledge and skills to develop and implement action plans to make PSE changes to target obesity

2. I have the knowledge and skills to conduct a community assessment, including gathering information from community and agency leaders about their views towards obesity and its prevention

3. I have the knowledge and skills to incorporate other projects that involve making PSE changes into my existing programmes

Supervisor behaviours

1. Develops connections in our community that directly facilitate my work

2 . Encourages me to develop my skills and interests ${ }^{(50)}$

3. Helps me secure funding for projects that involve using PSE approaches to address obesity

4. Is always available to meet with me when I seek help from him/her (50) $^{(2)}$

5. Helps me find more time to work on projects that involve using PSE approaches to address obesity

0.801

0.768

0.760

6. Understands what it means to use PSE approaches to address obesity

7. Encourages me to speak up when I disagree with a decision ${ }^{(50)}$

Agency resources

1. Agency partners who are committed to making PSE changes to target obesity

2. Agency partners who have resources (funding, staff) to make PSE changes to target obesity

0.884

0.840

0.816

3. Existing relationships with agency partners

Perceived community readiness

1. Leaders in my community are ready to do something about obesity ${ }^{(51)}$

0.851

0.826

0.759

0.816

0.711

0.700

0.668

2. The political and social climate in my community seems to be 'right' for starting collaborative projects that make PSE changes to target obesity ${ }^{(51)}$

3. Agencies in my community have a history of working together(51)

4. Technical support from funders

0.947

0.921

0.916

These four scales were rated on a 7-point scale of $1=$ 'strongly disagree' to $7=$ 'strongly agree ${ }^{\text {,(23) }}$, except obesity beliefs that were rated on a 5-point scale of $1=$ 'strongly disagree' to $5=$ 'strongly agree'. Factor loadings for all items ranged from 0.627 to 0.915 (Table 1). 
Table 2 Scale characteristics and mean scores for background factors and beliefs variables related to nutrition educators' use of policy, systems and environmental (PSE) strategies $(n 58)$

\begin{tabular}{|c|c|c|c|c|c|c|c|c|}
\hline \multirow[b]{2}{*}{ Scale/variable } & \multirow[b]{2}{*}{$\%$ Variance } & \multirow[b]{2}{*}{ Cronbach's a } & \multirow[b]{2}{*}{ KMO } & \multicolumn{2}{|c|}{ Bartlett's $(P<0.05)$} & \multirow[b]{2}{*}{ Possible score } & \multirow[b]{2}{*}{ Mean } & \multirow[b]{2}{*}{ SD } \\
\hline & & & & $x^{2}$ & df & & & \\
\hline \multicolumn{9}{|l|}{ Background factors } \\
\hline Networking & 63.5 & 0.85 & $0 \cdot 81$ & $132 \cdot 9$ & 10 & $1-7$ & $5 \cdot 3$ & $1 \cdot 1$ \\
\hline Persistence & $62 \cdot 3$ & 0.84 & 0.79 & $115 \cdot 3$ & 10 & $1-7$ & $5 \cdot 0$ & 1.0 \\
\hline Desire to do more & 60.5 & 0.75 & 0.70 & 68.5 & 6 & $1-7$ & 5.5 & 0.9 \\
\hline Obesity beliefs & $60 \cdot 3$ & 0.66 & 0.66 & $24 \cdot 8$ & 3 & $1-5$ & 3.5 & 0.7 \\
\hline \multicolumn{9}{|l|}{ Beliefs towards using PSE strategies } \\
\hline Impact on obesity prevention & $71 \cdot 8$ & 0.80 & 0.69 & $54 \cdot 7$ & 3 & $-3-+3$ & 1.6 & 0.2 \\
\hline \multicolumn{9}{|c|}{ Perceived social norms in using PSE strategies } \\
\hline Others' expectations & 58.4 & 0.88 & 0.85 & $192 \cdot 6$ & 21 & $-3-+3$ & $1 \cdot 2$ & $1 \cdot 2$ \\
\hline \multicolumn{9}{|c|}{ Perceived control in using PSE strategies } \\
\hline Personal knowledge and skills & $86 \cdot 2$ & 0.92 & 0.75 & $124 \cdot 4$ & 3 & $1-7$ & $5 \cdot 0$ & 0.9 \\
\hline Supervisor behaviours & $60 \cdot 0$ & 0.89 & 0.86 & 198.6 & 21 & $1-7$ & 4.5 & 1.3 \\
\hline Agency resources & 85.5 & 0.91 & 0.66 & $136 \cdot 7$ & 3 & $1-7$ & 4.8 & 1.4 \\
\hline Perceived community readiness & $66 \cdot 6$ & 0.83 & 0.72 & $97 \cdot 4$ & 6 & $1-7$ & 4.7 & 1.3 \\
\hline
\end{tabular}

$\mathrm{KMO}$, Kaiser-Meyer-Olkin measure of sampling adequacy.

Beliefs variables. Multiple beliefs variables assessed the three TPB constructs: beliefs towards using PSE strategies, other people's expectations of nutrition educators' use of PSE strategies and nutrition educators' perception of control in using PSE strategies. Factor loadings of the items ranged from 0.668 to 0.967 (Table 1). 'Beliefs towards using PSE strategies' (three items) assessed the extent of nutrition educators' belief that using PSE strategies positively impacts obesity prevention on a 7-point bipolar scale from $-3=$ 'strongly disagree' to $+3=$ 'strongly agree $^{,(24)}$. 'Others' expectations of nutrition educators in using PSE strategies' (seven items) assessed nutrition educators' perceived social pressure ${ }^{(24)}$ from others (e.g. colleagues, partners) to use PSE strategies. A 7-point bipolar scale from $-3=$ 'should not use strategy/strongly disagree' to $+3=$ 'should use strategy/strongly agree (24) $^{, 24}$ was used to assess this variable.

'Perceived control over using PSE strategies' was assessed with four scales regarding how much nutrition educators agreed that their personal knowledge and skills, supervisor behaviours, agency resources and community readiness were available to support their use of PSE strategies. Variables were evaluated on a 7-point unipolar scale from $1=$ 'strongly disagree' to $7=$ 'strongly agree ${ }^{\text {,(24) }}$. 'Personal knowledge and skills' (three items) assessed nutrition educators' performance of tasks related to using PSE strategies, including conducting assessments and incorporating PSE strategies into their programmes. 'Supervisor behaviours' (seven items) denoted the extent of nutrition educators' beliefs about their supervisors' support in their use of PSE strategies, including securing funding and developing community networks. 'Agency resources' (three items) referred to nutrition educators' evaluation of the extent of having partners who had the resources and were already working towards PSE changes to support healthy eating and physical activity. 'Perceived community readiness' (four items) assessed nutrition educators' perception that their community was ready to address obesity on the PSE levels.

\section{Statistical analyses}

The relationships among the multitude of factors associated with nutrition educators' use of PSE strategies were explored with multiple regression and bootstrapping methods using the statistical software package SPSS version 14.0 .2 (2006). The background factors were the independent variables, the set of beliefs were the mediators and nutrition educators' reported use of PSE strategies to prevent obesity was the dependent variable (Fig. 1). First, factor-based mean composite scores were calculated for the independent variables assessed with multiple items. Correlations, scatterplots and bivariate regression analyses were then performed to examine the variables and their relationships. Only significant variables in bivariate analyses were included in subsequent analyses.

Multiple regression was used to analyse mediation (indirect effects) with the causal steps approach ${ }^{(25)}$. The backward elimination method was applied to the group of background factors then the beliefs variables to identify the significant relationships. Because the causal steps approach had been criticized for its low power and method of inferring indirect effects by a series of hypothesis tests, the more valid and powerful bootstrapping technique was also applied ${ }^{(26)}$ to directly and simultaneously test the multiple mediators ${ }^{(27)}$.

Bootstrapping involved taking random samples of size $n$ from the original data and estimating the coefficients for the indirect paths from the independent variable to the mediating variables and from the mediating variables to the dependent variables ${ }^{(26)}$. The indirect effect was then computed by multiplying the coefficients for the two pathways for each sample. Random samples were returned to the pool to be reselected. This process was repeated $k=10000$ times to obtain a $95 \%$ CI sorted from 
the smallest to largest, in which the lower bound is in the 250th ordinal position and the upper bound is in the 9751st ordinal position. The present study reports the biascorrected confidence interval because it has consistently been found to be the most powerful test across conditions $^{(28)}$. The test was considered significant when the confidence interval did not contain zero.

Multiple regression analysis was further used to examine each two-way interaction individually. Moderating effects of the mediated relationships were examined using the bootstrapping method ${ }^{(29)}$. Resampling occurred 10000 times to derive the $95 \%$ CI for the conditional indirect effects at each value of the moderating variable (e.g. 1-7 for a 7-point response scale). The lower and upper levels of the interval along with the estimated coefficients were then plotted ${ }^{(29)}$.

\section{Results}

\section{Population characteristics}

Of fifty-eight participants, fifty-six were female; $7 \%$ were aged 35 years or below, $13 \%$ were aged $36-45$ years, $21 \%$ were aged $46-55$ years and $17 \%$ were aged 56 years or above; $28 \%$ had a bachelor's degree, 69\% a master's degree and $3 \%$ a doctorate. All participants managed a SNAP-Ed programme, with 53\% also managing EFNEP; additionally, ten nutrition educators managed a funded programme that specifically focused on PSE strategies; $10 \%$ reported not spending any time on PSE work, $62 \%$ spent $1-5 \mathrm{~h} /$ week, $17 \%$ spent $6-10 \mathrm{~h} /$ week and $10 \%$ spent more than $11 \mathrm{~h} /$ week on PSE work. Nutrition educators' tenure at their current position was $7 \cdot 7$ (SD 8.3) years; they managed 6.5 (SD 5.0) staff; and worked 43.1 (SD 8.0) h/ week. The summative score for using PSE strategies was $60 \cdot 2$ (sD 22.2; actual range 24-119; possible range 24-120) with a mode of $36 \cdot 0$. Table 2 shows that nutrition educators rated their networking, desire to do more in their work and persistence levels as moderate (5.0-5.5 on a scale of 1-7). Nutrition educators felt ambivalent about whether using PSE strategies contributes positively to obesity prevention (i.e. beliefs towards using PSE strategies) and slightly agreed that other people expect them to use PSE strategies and that individual factors, such as personal willpower, contribute to obesity. Further, nutrition educators slightly agreed that personal knowledge and skills, supervisor behaviour, agency resources and perceived community readiness were adequate for them to use PSE strategies.

\section{Test of mediation}

Figure 2 shows the empirical model with the mediated pathways and interactions that resulted from multiple regression and bootstrapping analyses. The main effects model (Model 1, Table 3) shows that having funds for PSE work was not significantly related to nutrition educators' use of PSE strategies. Further, a unit increase in networking and number of staff managed were associated with a corresponding increase in nutrition educators' use of PSE strategies. However, the more nutrition educators agreed that individual-level factors contributed to obesity, the less likely they were to use PSE strategies. Model 2 (Table 3) shows that an increase in others' expectations for nutrition educators to use PSE strategies and nutrition educators' perceptions of community readiness to use PSE strategies to prevent obesity were associated with increased strategy use. Regression analysis indicated that when the background factors and beliefs variables were combined into one model (Model 3, Table 3), the beliefs variables became non-significant. However, results from the more powerful bootstrapping method, which accounted for the two mediators simultaneously, revealed that the number

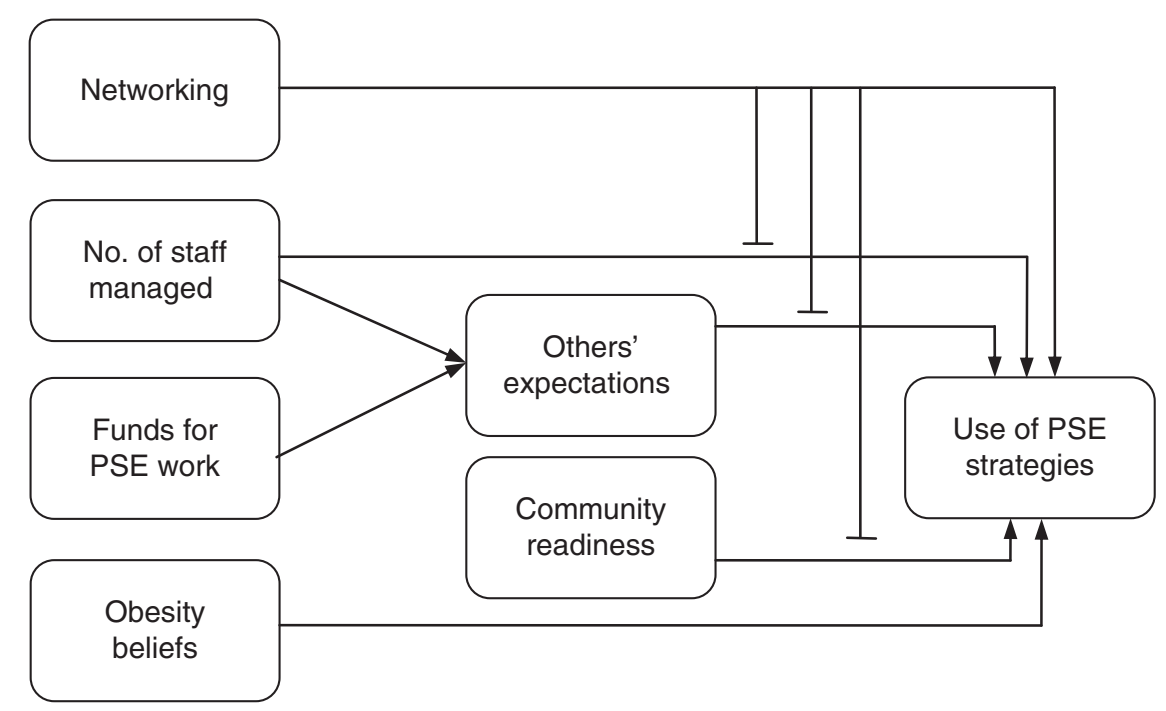

Fig. 2 Empirical model of nutrition educators' use of policy, systems and environmental (PSE) strategies showing the results of mediation and moderation analyses $(n 58)$. Lines ending in an arrow indicate direct associations; those ending in a horizontal mark indicate moderation effect 
Table 3 Unstandardized coefficients $(B)$, standard errors, $95 \%$ confidence intervals and model statistics for main effects and mediator models predicting nutrition educators' use of policy, systems and environmental (PSE) strategies $(n 58)$

\begin{tabular}{|c|c|c|c|c|c|c|c|c|c|c|c|c|c|c|}
\hline & \multicolumn{6}{|c|}{$\begin{array}{l}\text { Dependent variable: Reported use } \\
\text { of PSE strategies }\end{array}$} & \multirow{2}{*}{\multicolumn{4}{|c|}{$\begin{array}{c}\begin{array}{c}\text { Dependent variable: Others' } \\
\text { expectations } \dagger\end{array} \\
\text { Model } 4\end{array}$}} & \multirow{2}{*}{\multicolumn{4}{|c|}{$\begin{array}{c}\text { Dependent variable: Perceived } \\
\text { community readiness } \dagger\end{array}$}} \\
\hline & \multicolumn{2}{|c|}{ Model 1} & \multicolumn{2}{|c|}{ Model 2} & \multicolumn{2}{|c|}{ Model 3} & & & & & & & & \\
\hline & $B$ & $\mathrm{SE}$ & $B$ & $\mathrm{SE}$ & $B$ & $\mathrm{SE}$ & $B$ & SE & Lower & Upper & $B$ & SE & Lower & Upper \\
\hline \multicolumn{15}{|l|}{ Background factors } \\
\hline Networking & $6 \cdot 05^{\star}$ & 2.38 & _- & - & $4.90^{*}$ & $2 \cdot 29$ & 0.06 & 0.15 & -0.32 & 2.53 & 0.26 & 0.16 & -0.03 & $2 \cdot 87$ \\
\hline No. of staff managed & $1 \cdot 36^{\star}$ & 0.50 & - & - & $1.04^{*}$ & 0.48 & 0.06 & 0.03 & 0.04 & 0.68 & 0.03 & 0.03 & -0.08 & 0.43 \\
\hline Funds for PSE work & 11.33 & $5 \cdot 71$ & - & - & 5.51 & $5 \cdot 69$ & $0.80^{*}$ & 0.37 & 0.19 & $8 \cdot 19$ & 0.75 & 0.37 & -0.81 & 7.50 \\
\hline Obesity beliefs & $-7.58^{\star}$ & 3.61 & - & - & $-6 \cdot 45$ & 3.49 & 0.06 & 0.23 & -1.96 & $2 \cdot 17$ & -0.38 & 0.24 & -4.39 & 0.21 \\
\hline \multicolumn{15}{|l|}{ Beliefs variables } \\
\hline Others' expectations & - & - & $6 \cdot 00^{*}$ & $2 \cdot 22$ & 3.87 & $2 \cdot 10$ & - & - & - & - & - & - & - & - \\
\hline Community readiness & - & - & $6 \cdot 91^{*}$ & $2 \cdot 12$ & $3 \cdot 64$ & 2.06 & - & - & - & - & - & - & - & - \\
\hline Intercept & $42 \cdot 74$ & $15 \cdot 26$ & $20 \cdot 89^{*}$ & $9 \cdot 39$ & 26.99 & $16 \cdot 79$ & 0.06 & 0.98 & - & - & 4.27 & 1.00 & - & - \\
\hline Adjusted $R^{2}$ & \multicolumn{2}{|c|}{0.41} & \multicolumn{2}{|c|}{0.34} & \multicolumn{2}{|c|}{0.48} & \multicolumn{4}{|c|}{0.16} & \multicolumn{4}{|c|}{0.26} \\
\hline
\end{tabular}

${ }^{*} P<0.05$

†Results from using the bootstrapping method.

Table 4 Unstandardized coefficients $(B)$, standard errors and model statistics for models with interaction terms predicting nutrition educators' use of policy, systems and environmental (PSE) strategies ( $n$ 58)

\begin{tabular}{|c|c|c|c|c|c|c|}
\hline & \multicolumn{6}{|c|}{ Dependent variable: Reported use of PSE strategies } \\
\hline & \multicolumn{2}{|c|}{ Model 1} & \multicolumn{2}{|c|}{ Model 2} & \multicolumn{2}{|c|}{ Model 3} \\
\hline & $B$ & $\mathrm{SE}$ & $B$ & SE & $B$ & $\mathrm{SE}$ \\
\hline \multicolumn{7}{|l|}{ Background factors } \\
\hline Networking & -0.76 & 3.43 & 0.35 & 2.93 & -15.98 & $10 \cdot 13$ \\
\hline No. of staff managed & $-5 \cdot 18$ & 2.92 & 0.92 & 0.46 & 0.82 & 0.48 \\
\hline Funds for PSE work & 3.77 & 5.56 & 3.03 & 5.56 & 3.65 & 5.58 \\
\hline Obesity beliefs & $-7 \cdot 19^{\star}$ & 3.39 & -5.90 & 3.35 & $-8 \cdot 72^{*}$ & 3.54 \\
\hline \multicolumn{7}{|l|}{ Beliefs variables } \\
\hline Others' expectations & $4 \cdot 60^{\star}$ & $2 \cdot 06$ & $-20 \cdot 34$ & $10 \cdot 53$ & $4 \cdot 85^{\star}$ & 2.09 \\
\hline Community readiness & 3.58 & 1.99 & $3.98^{\star}$ & 1.98 & $-23 \cdot 77$ & $13 \cdot 13$ \\
\hline \multicolumn{7}{|l|}{ Interactions } \\
\hline Network $\times$ no. of staff managed & $1.04^{*}$ & 0.48 & - & - & - & - \\
\hline Network $\times$ others' expectations & - & - & $4 \cdot 64^{\star}$ & 1.98 & - & - \\
\hline Network $\times$ community readiness & - & - & - & - & $4 \cdot 89^{\star}$ & $2 \cdot 32$ \\
\hline Intercept & $62 \cdot 44^{\star}$ & 23.09 & $47 \cdot 32^{*}$ & $18 \cdot 28$ & $151 \cdot 40^{\star}$ & 61.09 \\
\hline Adjusted $R^{2}$ & \multicolumn{2}{|c|}{0.52} & \multicolumn{2}{|c|}{0.52} & \multicolumn{2}{|c|}{0.51} \\
\hline
\end{tabular}

${ }^{*} P<0.05$.

of staff nutrition educators managed and having funds for PSE work were also indirectly associated with nutrition educators' use of PSE strategies through others' expectations (Model 4, Table 3), but not through perceived community readiness (Model 5, Table 3).

\section{Test of interactions}

Results of testing for interactions (Table 4) consistently revealed networking as an essential variable that moderated multiple pathways (Fig. 2), including the direct associations of number of staff managed (Model 1, Table 4) and perceived community readiness (Model 3, Table 4) with reported use of PSE strategies, as well as the mediated pathways through others' expectations (Model 2, Table 4). These sets of relationships depended on the extent of nutrition educators' networking in their communities towards programme goals.
The negative coefficients for number of staff nutrition educators managed, others' expectations and perceived community readiness in Models 1, 2 and 3 (Table 4), respectively, mean that when networking $=0$, an increase in these variables is associated with a decrease in nutrition educators' use of PSE strategies. Further, when number of staff nutrition educators managed and others' expectations equalled zero (Models 1 and 2, respectively, Table 4), an increase in networking was associated with only a slight change ( $B=-0.764$ and 0.347 , respectively) in PSE strategy use; but when perceived community readiness equalled zero, an increase in networking was actually associated with a greater decrease $(B=-15.982)$ in strategy use. This means that when nutrition educators managed few staff and did not perceive that other people expected them to use PSE strategies, networking did not result in their use of PSE strategies. However, a unit 


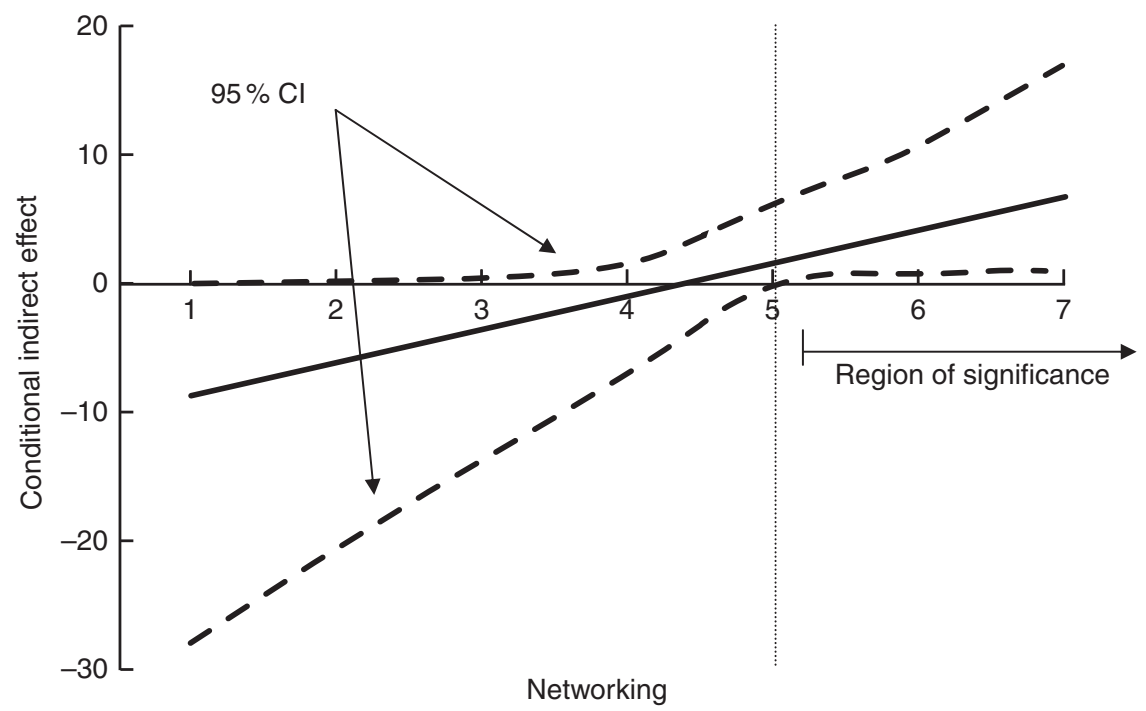

Fig. 3 Plot of the indirect relationship (mediated by others' expectations) between having funds for policy, systems and environmental (PSE) work and use of PSE strategies at various levels of networking ( $n$ 58). Vertical dotted line indicates networking level at which the relationship between having funds for PSE work and use of PSE strategies mediated through others' expectations occurred

increase in community readiness is associated with the largest slope increase in networking (Model 3, Table 4). In other words, when the community is perceived to be ready to use PSE strategies, nutrition educators were able to capitalize on the network of relationships to make PSE changes in the community.

The plot of conditional indirect effects (Fig. 3) shows that the relationship between having funds for PSE work and use of PSE strategies mediated through others' expectations occurred at levels of networking greater than 5 (near the mean of 5.3 on a scale of $1-7$ ). Results were similar when the independent variable was number of staff managed. It is only at moderately high levels of networking, also greater than 5 on a scale of $1-7$, that having staff and funds for PSE work are positively associated with nutrition educators' use of PSE strategies.

\section{Discussion}

Results of the present study partially supported the TPB principle that associations between background factors and behaviour are mediated through people's beliefs and attitude towards the behaviour and perceived social norms related to and control over performing the behaviour ${ }^{(19)}$. Nutrition educators' reported use of PSE strategies to prevent obesity was positively associated with their community networking (as Stark et $a l .{ }^{(30)}$ also found), number of staff they managed, other people's expectations of them to make PSE changes and their perception that their communities were ready to use PSE strategies. Yet, the relationships among these variables were complicated and depended significantly on the extent of nutrition educators' networking in their communities. Their use of PSE strategies occurred only when they utilized their professional networks at a moderately high level, given that their community was also ready to use PSE strategies.

The interactions between networking and other variables corroborated qualitative results. For example, nutrition educators described that having more staff allowed them to be more involved in work to promote PSE changes, partly because the relationships established by their staff contributed to nutrition educators' networking for PSE work. Having more staff also reflects programme maturity and operational capacity ${ }^{(17)}$, as nutrition educators reported their staff relieving them of the more routine tasks associated with programmes focused on individual-level changes. Nutrition educators also described characteristics of effective non-profit organizations, including being a mature organization with stable funding and a history of commitment to its constituencies, and having a collaborative rather than competitive mindset ${ }^{(31)}$ and positive reputation among other agencies in the region ${ }^{(17)}$, as reasons for their engagement in PSE projects.

Additionally, the finding on perceived community readiness, considered one of the significant variables used to assess perception of control, was consistent with that of previous research that applied the $\mathrm{TPB}^{(32)}$. The significance of others' expectations of nutrition educators in using PSE strategies as a mediating variable was also consistent with previous research where social norms were a significant determinant of individuals' business succession planning ${ }^{(33)}$. Nutrition educators claimed that their personal connections with people, an important means for community members to become collaborators ${ }^{(34)}$, exposed them to or allowed them to connect with partners interested in PSE work and to gauge the community's readiness to do PSE work. These encounters often led to coordinated planning and implementation of PSE 
activities and mobilization and allocation of resources ${ }^{(35)}$, such as applying for grants and develop and implement community-wide food systems to improve people's access to healthy foods ${ }^{(20)}$. However, as important as networking is to build trust and to enhance community involvement ${ }^{(36,37)}$, it is still an infrequently practised skill ${ }^{(38)}$ because it requires a significant amount of time and energy ${ }^{(39,40)}$.

The belief that individual factors contribute to obesity was negatively associated with nutrition educators' reported strategy use, consistent with the TPB principle that actions are likely to occur when beliefs are positive ${ }^{(19)}$. Having funds allocated to PSE work was not directly associated with nutrition educators' strategy use, but contributed to their perception that other people expected them to use PSE strategies. Contrarily, some variables were not statistically significant in multivariate models, including nutrition educators' current tenure, hours of work each week, level of persistence, desire to do more in their work, supervisor behaviours and agency resources. This may be due to low variance and lack of power due to the small sample size. However, these variables hold practical significance. For example, nutrition educators' tenure mattered because the longer they worked in their communities, the better they knew people and the more established working relationships they had with other agencies, some of which led to collaborations that focused on making PSE changes. Moreover, longer tenure may lead people to engage more in social-oriented tasks such as networking and maintaining relationships with community partners and devote more time and skills to experimenting with new approaches ${ }^{(41)}$, such as using PSE strategies to prevent obesity.

While the present study adopted the TPB framework to examine the behaviours of nutrition educators in using PSE strategies, its cross-sectional results do not imply causality among the variables and are not intended to be generalized across different populations of community nutrition educators and in different settings. Instead, the study simply revealed the significant factors and possible mechanisms related to community practitioners' work in applying PSE approaches to prevent obesity. While the TPB theoretically illustrated these relationships to be linear and unidirectional, triangulation of qualitative and quantitative results implied it is more likely in practice that the associations among some variables are reciprocal and mutually reinforcing, such as the influences among concepts in any system ${ }^{(42)}$. For example, although nutrition educators' reported use of PSE strategies was the dependent variable, nutrition educators' experiences in using PSE strategies would likely contribute positively in shaping their beliefs towards the causes and prevention of obesity, as changing individuals' behaviour is an effective way to alter their attitude and beliefs ${ }^{(43)}$.

In addition to using a mixed-methods approach to triangulate research findings, the present study was grounded in current programming with practitioners in the field providing their perceptions and practices in using PSE strategies that reflect local realities. Content validity was enhanced by input from SNAP-Ed leadership and former nutrition educators who pilot-tested the draft survey. While the number of nutrition educators was limited and data were self-reported, and thus subject to possible recall and estimation errors or social desirability bias, results were strengthened by the $100 \%$ response rate of the nutrition educators in Cornell Cooperative Extension at the time of the study. Further, the more powerful bootstrapping approach ${ }^{(26)}$ was applied in statistical analyses to complement regression analysis in revealing others' expectations as the mediator in this model and the extent of networking as a significant factor associated with nutrition educators' use of PSE strategies.

\section{Implications for research and practice}

In research, the current mixed-methods study, including scales within the survey, can be applied to examine the perspectives and practices of other stakeholders involved in community-based health programmes targeting obesity, including public health practitioners, to better understand the capacities of communities to address multifaceted problems $^{(44)}$. As community stakeholders have become more aware of the need for more cross-sectoral collaborations $^{(14,16)}$, community and public health professionals need to continue to develop skills that contribute to the success in networking, including socializing, politicking and interacting with others ${ }^{(45)}$. Further, as practitioners continue to perceive the environment's impact on people's health and work towards creating PSE changes that facilitate and promote healthful food choices, their beliefs towards using PSE strategies as necessary for obesity prevention will be strengthened, along with skills and expertise necessary to become more effective at networking and ultimately bringing about PSE changes in organizations and communities where they work. Organizations need to make supportive changes such as modifying job expectations and scope of responsibilities, providing necessary resources and creating conditions that motivate practitioners to broaden their activities and engage in action to change environments. These shifts will ultimately contribute to improving the nutrition and health of the population.

\section{Acknowledgements}

Acknowledgements: The authors thank the nutrition educators in Cornell Cooperative Extension who assisted in the development of and were interviewed and surveyed in this study. They also thank Francoise Vermeylen for offering valuable insights and guidance with data analysis. Financial support: This work was part of the doctoral research of A.H.L. with financial support provided by a National Institutes of Health (NIH) Training Grant 
(number T32-DK-00715832). The NIH had no role in the design, analysis or writing of this article. Conflict of interest: None. Authorship: A.H.L., K.L.D. and J.S.D. formulated the research questions and designed the study. A.H.L. collected and analysed the data. All authors drafted and critically reviewed the manuscript. They approved and submitted the final version for publication. Etbics of buman subject participation: This study was approved by the Cornell University Institutional Review Board and informed consent was obtained from each participant.

\section{References}

1. Cheadle A, Rauzon S \& Schwartz PM (2014) Communitylevel obesity prevention initiatives: impact and lessons learned. Natl Civ Rev 103, 35-39.

2. Kumanyika S, Jeffery RW, Morabia A et al. (2002) Obesity prevention: the case for action. Int $J$ Obes Relat Metab Disord 26, 425-436.

3. Sanigorski AM, Bell AC, Kremer PJ et al. (2008) Reducing unhealthy weight gain in children through community capacity-building: results of a quasi-experimental intervention program, Be Active Eat Well. Int J Obes (Lond) 32, 1060-1067.

4. Coffield E, Nihiser AJ, Sherry B et al. (2015) Shape Up Sommerville: change in parent body mass indexes during a child-targeted, community-based environmental change intervention. Am J Public Health 105, e83-e89.

5. Centers for Disease Control and Prevention (2009) Recommended community strategies and measurements to prevent obesity in the United States. MMWR Recomm Rep 58, $1-29$.

6. Institute of Medicine (2005) Preventing Childhood Obesity: Health in the Balance. Washington, DC: National Academies Press; available at http://www.ncbi.nlm.nih.gov/ books/NBK83825/

7. New York State Department of Health (2016) Prevention agenda 2013-2018: preventing chronic diseases action plan. http://www.health.ny.gov/prevention/prevention_agenda/ 2013-2017/plan/chronic_diseases/focus_area_1.htm (accessed June 2017).

8. US Department of Agriculture, National Institute of Food and Agriculture (2015) NIFA Strategic Plan FY2014-FY2018. https://nifa.usda.gov/resource/nifa-strategic-plan-fy2014-fy 2018 (accessed June 2017).

9. US Department of Agriculture, Food and Nutrition Service (2017) SNAP-Ed plan guidance FY 2017. https://snaped.fns. usda.gov/national-snap-ed/snap-ed-plan-guidance-andtemplates (accessed June 2017).

10. Ogden CL, Carroll MD, Kit BK et al. (2014) Prevalence of childhood and adult obesity in the United States, 2011-2012. JAMA 311, 806-814.

11. Fagen MC, Asada Y, Welch S et al. (2014) Policy, systems, and environmentally oriented school-based obesity prevention: opportunities and challenges. J Prev Interv Community 42, 95-111.

12. Centers for Disease Control and Prevention (2015) PCD collection: communities putting prevention to work (CPPW). http://www.cdc.gov/pcd/collections/ (accessed February 2016).

13. McLeroy KR, Bibeau D, Steckler A et al. (1988) An ecological perspective on health promotion programs. Health Educ Q 15, 351-378.
14. Ganter C, Aftosmes-Tobio A, Chuang E et al. (2015) Community stakeholders' perceptions of major factors influencing childhood obesity, the feasibility of programs addressing childhood obesity, and persisting gaps. J Community Health 41, 305-314.

15. Yngve A (2006) Challenges for public health nutrition are immense - to be a good public health nutrition leader requires networking and collaboration. Public Health Nutr 9, 535-537.

16. Gantner LA \& Olson CM (2012) Evaluation of public health professionals' capacity to implement environmental changes supportive of healthy weight. Eval Program Plann 35, 407-416.

17. Fredericksen P \& London R (2000) Disconnect in the hollow state: the pivotal role of organizational capacity in community-based development organizations. Public Admin Rev 60, 230-239.

18. Zakocs RC \& Edwards EM (2006) What explains community coalition effectiveness? A review of the literature. Am J Prev Med 30, 351-361.

19. Ajzen I \& Albarracín D (2007) Predicting and changing behavior: a reasoned action approach. In Prediction and Change of Health Behavior: Applying the Reasoned Action Approach, pp. 3-21 [I Ajzen, D Albarracín and R Hornik, editors]. Mahwah, NJ: Lawrence Erlbaum Associates.

20. Lu AH, Dickin K \& Dollahite J (2014) Development and application of a framework to assess community nutritionists' use of environmental strategies to prevent obesity. J Nutr Educ Behav 46, 475-483.

21. DeVellis RF (2003) Scale Development: Theory and Applications, 2nd ed. Thousand Oaks, CA: SAGE Publications, Inc.

22. Francis JJ, Eccles MP, Johnston J et al. (2004) Constructing Questionnaires Based on the Theory of Planned Behaviour: A Manual for Health Services Research. Newcastle upon Tyne: Centre for Health Services Research, University of Newcastle upon Tyne; available at http://openaccess.city. ac.uk/1735/

23. Gagne C \& Godin G (2000) The theory of planned behavior: some measurement issues concerning belief-based variables. J Appl Soc Psychol 30, 2173-2193.

24. Ajzen I (1991) The theory of planned behavior. Organ Behav Hum Decis Process 50, 179-211.

25. Baron RM \& Kenny DA (1986) The moderator-mediator distinction in social psychological research: conceptual, strategic, and statistical considerations. J Pers Soc Psychol 51, 1173-1182.

26. Hayes AF (2009) Beyond Barron and Kenny: statistical mediation analysis in the new millennium. Commun Monogr 76, 408-420.

27. Preacher KJ \& Hayes AF (2008) Contemporary approaches to assessing mediation in communication research. In The Sage Sourcebook of Advanced Data Analysis Methods for Communication Research, pp. 13-54 [AF Hayes, MD Slater and LB Snyder, editors]. Thousand Oaks, CA: SAGE Publications, Inc; available at http://www.sagepub.com/ upm-data/23657_Chapter2.pdf

28. Fritz MS \& MacKinnon DP (2007) Required sample size to detect the mediated effect. Psychol Sci 18, 233-239.

29. Preacher KJ, Rucker DD \& Hayes AF (2007) Addressing moderated mediation hypotheses: theory, methods, and prescriptions. Multivariate Behav Res 42, 185-227.

30. Stark CM, Devine CM \& Dollahite JS (2017) Characteristics associated with the application of an ecological approach to preventing childhood obesity. Public Health Nutr 20, 174-183.

31. Provan KG \& Milward HB (1995) A preliminary theory of interorganizational network effectiveness: a comparative study of four community mental health systems. Admin Sci $Q \mathbf{4 0}, 1-33$.

32. Godin G \& Kok G (1996) The theory of planned behavior: a review of its applications. Am J Health Promot 11, 87-98. 
33. Sharma P, Chrisman JJ \& Chua JH (2003) Succession planning as planned behavior: some empirical results. Fam Bus Rev 16, 1-16.

34. Bassett EM \& Glandon RP (2008) Influencing design, promoting health. J Public Health Manag Pract 14, 244-254.

35. Wendel ML, Prochaska JD, Clark HR et al. (2010) Interorganizational network changes among health organizations in the Brazos Valley, Texas. J Prim Prev 31, 59-68.

36. Dowling B, Powell M \& Glendinning C (2004) Conceptualising successful partnerships. Health Soc Care Community 12, 309-317.

37. Seifer SD (2006) Building and sustaining communityinstitutional partnerships for prevention research: findings from a national collaborative. J Urban Health 83, 989-1003.

38. Baxter RJ (2010) Making better use of the policies and funding we already have. Prev Chronic Dis 7, A97.

39. Kreuter MW, Lezin NA \& Young LA (2000) Evaluating community-based collaborative mechanisms: implications for practitioners. Health Promot Pract 1, 49-63.

40. Wilensky AS \& Hansen CD (2001) Understanding the work beliefs of nonprofit executives through organizational stories. Hum Resour Dev Q 12, 223-239.

41. Ng TWH \& Feldman DC (2010) Organizational tenure and job performance. J Manag 36, 1220-1250.

42. Tseng V \& Seidman E (2007) A systems framework for understanding social settings. Am J Community Psychol 39 , 217-228.

43. Bem DJ (1970) Beliefs, Attitudes and Human Affairs. Belmont, CA: Brooks/Cole Publishing.
44. Feinberg ME, Greenberg MT \& Osgood DW (2004) Readiness, functioning, and perceived effectiveness in community prevention coalitions: a study of communities that care. Am J Community Psychol 33, 163-176.

45. Asllani A \& Luthans F (2003) What knowledge managers really do: an empirical and comparative analysis. J Knowl Manag 7, 53-66.

46. Ferris GR, Treadway DC, Kolodinsky RW et al. (2005) Development and validation of the political skill inventory. J Manag 31, 126-152.

47. Bateman TS \& Crant JM (1993) The proactive component of organizational behavior: a measure and correlates. J Organ Behav 14, 103-118.

48. Oliver JE \& Lee T (2005) Public opinion and the politics of obesity in America. J Health Polit Policy Law 30, 923-954.

49. Barry CL, Brescoll VL, Brownell KD et al. (2009) Obesity metaphors: how beliefs about the causes of obesity affect support for public policy. Milbank $Q \mathbf{8 7}$, $7-47$.

50. Cammann C, Fichman M, Jenkins GD et al. (1983) Assessing the attitudes and perceptions of organizational members. In Assessing Organizational Change: A Guide to Methods, Measures, and Practices, pp. 71-138 [SE Seashore, EE Lawler, PH Mirvis et al., editors]. New York: John Wiley and Sons.

51. Mattessich PW, Murray-Close M \& Monsey BR (2001) Collaboration: What Makes It Work. St. Paul, MN: Amherst H. Wilder Foundation. 